\title{
Haustorial Function During Development of Cleistothecia in Blumeria graminis f. sp. tritici
}

\author{
Monika Götz and Christine Boyle, Institute of Microbiology TU Braunschweig, Spielmannstr. 7, D-38106 \\ Braunschweig, Germany
}

\begin{abstract}
Götz, M., and Boyle, C. 1998. Haustorial function during development of cleistothecia in Blumeria graminis f. sp. tritici. Plant Dis. 82:507-511.

Cleistothecia of Blumeria graminis are a means of survival under adverse conditions as well as a means of sexual reproduction, and are produced by the generative mycelium at the end of the vegetation period. Vital stains and ${ }^{14} \mathrm{C}$-labeled sucrose were transported from the host (Triticum aestivum) through the haustoria into the generative mycelium. Translocation was intense during the early developmental stage of the generative mycelium. Colonies of later stages with macroscopically visible developing cleistothecia showed reduced staining and labeling. This correlated with an increase in the number as well as the degree of haustorial encasement and papillae formation. Detached mycelia of later developmental stages produced ripe cleistothecia containing ascospores of high germination rates in vitro, but early stages with microscopically small primordia only developed dark fruit bodies that did not produce ascospores. The data indicate that nutrition supply by the host is essential at the early stages of the generative mildew mycelium. The resulting metabolites are mainly stored within the hyphae. At later developmental stages, the generative mycelium progressively becomes more independent of nutrition supply by the host, providing its own metabolites for the growing fruit bodies.
\end{abstract}

Additional key words: haustorium, nutrition, powdery mildew, translocation

Besides vegetative sporulation (conidia), powdery mildew fungi produce cleistothecia for sexual recombination and as a means of surviving unsuitable conditions. As an obligately biotrophic fungus, the powdery mildew of wheat (Blumeria graminis (DC.) Speer f. sp. tritici) needs a living host for its development. By means of haustoria, the fungus invaginates the epidermal cell plasmalemma which, as an extrahaustorial membrane, expresses chemical, physical, and functional properties different from those of a typical plant plasmalemma $(5,26,28)$. In compatible interactions, the parasite overcomes the defense reactions of its host and induces a selective directional nutrient flux to its mycelia.

Due to its epidemiological relevance to yield loss, many investigations have been done on the vegetative stage of the pathogen $(24,31,35)$. Studies of the sexual stage have mainly clarified the environmental conditions essential for its expression $(9,14,25,29,43)$. This paper provides evi-

\section{Corresponding author: C. Boyle \\ E-mail: C.Boyle@TU-BS.DE}

This work was supported by the Deutsche Forschungsgemeinschaft (DFG).

Accepted for publication 19 January 1998.

Publication no. D-1998-0319-04R

(C) 1998 The American Phytopathological Society dence of haustorial transport throughout the entire sexual stage of the powdery mildew of wheat, and the extent to which the generative mycelium is dependent on nutrient supply by the host.

\section{MATERIALS AND METHODS}

Winter wheat (Triticum aestivum L.). Field plants of winter wheat cv. Kanzler were grown using standard fertilizer (160 $\mathrm{kg} \mathrm{ha}^{-1}$ nitrogen) without fungicide application. B. graminis developed its generative stages from the middle of May until harvest of the crop (16). The leaves below the flag leaf, infected with generative mycelium $(\approx 50 \%$ of the leaf area as a minimum), 90 to $95 \%$ of which showed growth of one generative stage of powdery mildew, were used for translocation experiments and in vitro development of cleistothecia.

Powdery mildew (B. graminis (DC.) Speer f. sp. tritici). Developmental stages of the generative mycelium (gm) were macroscopically categorized as gm1, elevated white mycelium with strongly reduced conidiogenesis and as yet without discernible fruit bodies; gm2, white mycelium bearing young whitish cleistothecia; and $\mathrm{gm} 3$, brownish to black cleistothecia (Fig. 1A to C).

Mycelia of each stage were separated from the host leaves with fine forceps and incubated in a moist chamber at $15^{\circ} \mathrm{C}$ in the dark for microscopic study of further fruit body and ascospore development (Fig. 1; 16).

Translocation of stain and ${ }^{14} \mathrm{C}$-sucrose. Ten leaves each, either infected primarily with one stage of the generative mycelium (gm1 to 3 ) or uninfected, were cut off under water and immediately transferred into glass tubes with $1 \mathrm{ml}$ stain solution, ${ }^{14} \mathrm{C}$-sucrose solution, or water (control), and incubated for 3 days under standard conditions in climate chambers (Weiß Technik GmbH, Reiskirchen, Germany): $18^{\circ} \mathrm{C}, 70 \%$ relative humidity ( $\left.\mathrm{RH}\right)$ 16:8 h light:dark, photosynthetically active radiation (PAR) $210 \mu \mathrm{mol} \mathrm{m} \mathrm{m}^{-2}$.
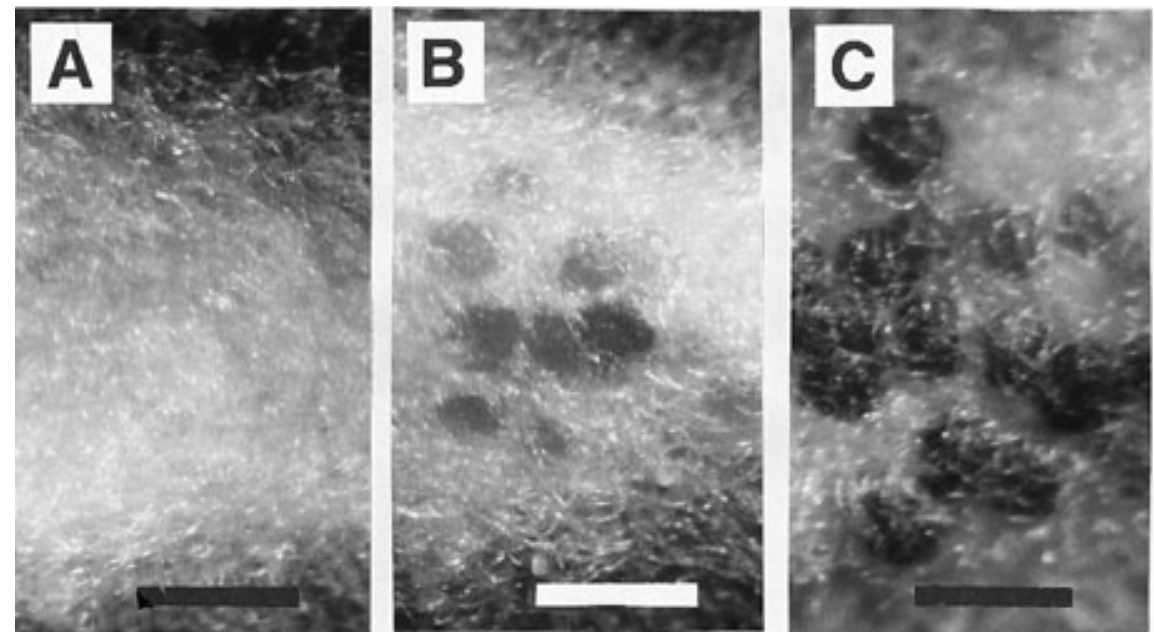

Fig. 1. Different stages of generative mycelium development of Blumeria graminis under field conditions: (A) generative mycelium (gm) stage 1; (B) gm2; (C) gm3. Bar $=500 \mu \mathrm{m}$, arrows $=$ fruit bodies. 
Since it can be transported within a wheat leaf as well as translocated to the mycelium, sodium fluorescein $(0.01 \%$ in sterile distilled water) proved to be the most suitable stain. As an important transport-carbohydrate within plants $(32,34)$, sucrose was used at a concentration of 0.75 pmol mi ${ }^{-1}{ }^{14} \mathrm{C}$-sucrose $(\mathrm{NEC}-100 \times$ sucrose, Du Pont GmbH, NEN division,
Dreikirchen, Germany) in sterile distilled water $\left(\cong 0.5 \mu \mathrm{Ci} \mathrm{ml}^{-1}\right)$.

At the end of the incubation period, the staining was examined using a fluorescence microscope (BH-2, Olympus, Hamburg, Germany) with a filter combination (DM-400 + filter 420, DM-500 + filter O 515). Samples containing detached mycelia of one stage each were either measured for

Table 1. ${ }^{14} \mathrm{C}$-sucrose $\left(0.75 \mathrm{pmol} \mathrm{ml}^{-1}\right)$ incorporation into leaf and fungal material following a 3-day incubation ${ }^{\mathrm{w}}$ of mildew-infected and non-infected wheat leaves

\begin{tabular}{|c|c|c|c|}
\hline Material & Developmental stage & ${ }^{14} \mathrm{C}$-activity $\left(\mathrm{Bq} \mathrm{g}^{-1} \text { fresh weight }\right)^{\mathrm{x}}$ & Comparison $^{y}$ \\
\hline \multirow[t]{4}{*}{ Wheat leaf } & Non-infected control & $6.6 \pm 1.2$ & $\mathrm{a}$ \\
\hline & $\mathrm{gm} 1^{\mathrm{z}}$ & $399.1 \pm 48.0$ & $\mathrm{~b}$ \\
\hline & $\operatorname{gm} 2$ & $283.5 \pm 40.5$ & $\mathrm{c}$ \\
\hline & gm3 & $197.3 \pm 13.2$ & $\mathrm{c}$ \\
\hline \multirow{3}{*}{ Generative stage } & gm1 & $8772.1 \pm 32.1$ & $\mathrm{~d}$ \\
\hline & gm2 & $3150.8 \pm 191.9$ & $\mathrm{e}$ \\
\hline & gm3 & $939.5 \pm 91.3$ & $\mathrm{f}$ \\
\hline
\end{tabular}

${ }^{\mathrm{w}} 18^{\circ} \mathrm{C}, 70 \%$ relative humidity, $16: 8 \mathrm{~h}$ light:dark, photosynthetically active radiation $210 \mu \mathrm{mol} \mathrm{m}^{-2} \mathrm{~s}^{-1}$.

$x$ Mean and standard error $( \pm)$ of three separately measured pooled samples.

y Different letters mark significant differences $(P<0.05)$ as compared by the Student-Newman-Keuls Method, after one-way analysis of variance.

z Generative mycelium (gm) stages 1, 2, and 3 .
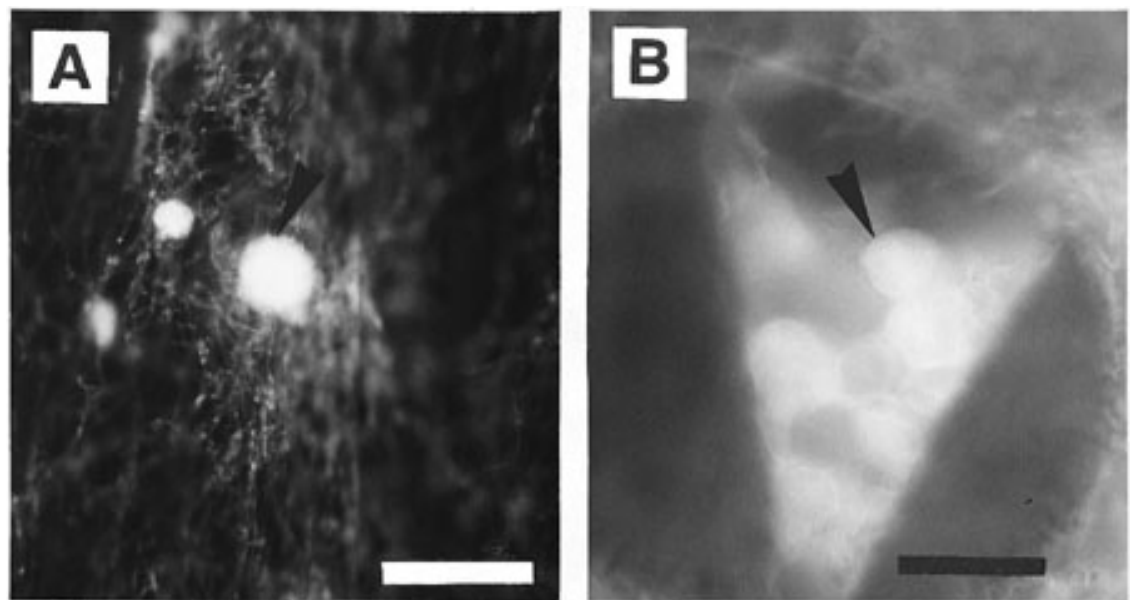

Fig. 2. (A) Generative mycelium (gm) stage 1 (arrow = primordium) and (B) gm 3 (arrow = asci) of Blumeria graminis after incubation in sodium fluorescein $(0.01 \%)$ for 3 days $\left(18^{\circ} \mathrm{C}, 70 \%\right.$ relative humidity, 16:8 h light:dark, photosynthetically active radiation $210 \mu \mathrm{mol} \mathrm{m}^{-2} \mathrm{~s}^{-1}$ ). Bar $=100 \mu \mathrm{m}$.
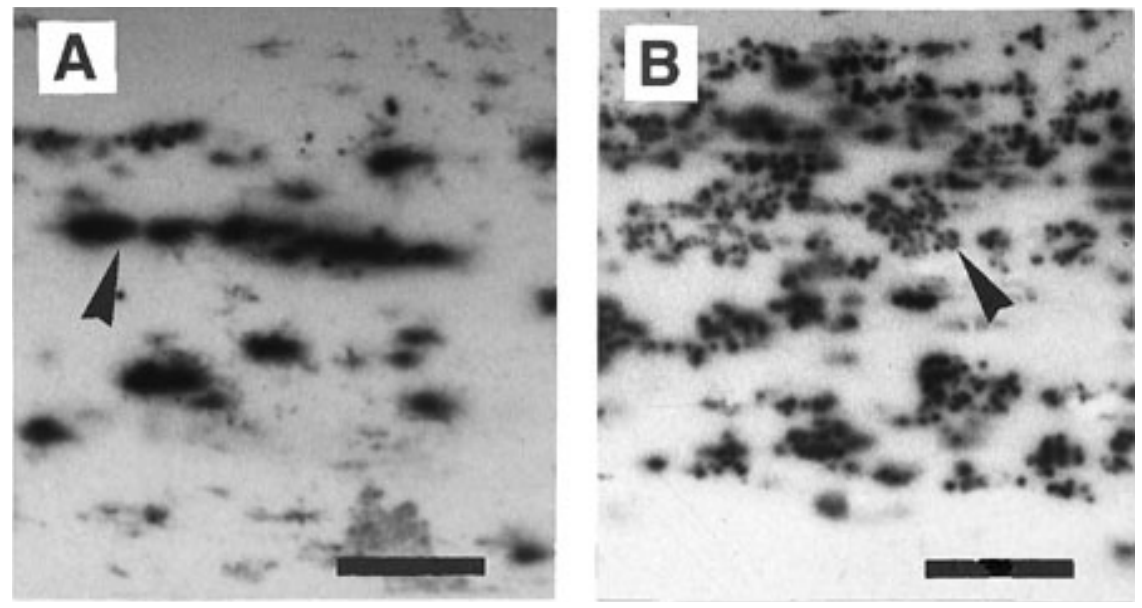

Fig. 3. X-ray film analysis of generative mycelium (gm) stages after incubation using ${ }^{14} \mathrm{C}$-sucrose $\left(0.75 \mathrm{pmol} \mathrm{ml}^{-1}\right)$ of mildew-infected wheat leaves $\left(18^{\circ} \mathrm{C}, 70 \%\right.$ relative humidity, $16: 8 \mathrm{~h}$ light:dark, photosynthetically active radiation $210 \mu \mathrm{mol} \mathrm{m}^{-2} \mathrm{~s}^{-1}$ ). (A) gm1, arrow $=$ colony showing an equal distribution of ${ }^{14} \mathrm{C} ;(\mathbf{B})$ gm3, cleistothecia with high ${ }^{14} \mathrm{C}$ activity. Bar $=4 \mathrm{~mm}$. quantitative radioactivity by carefully preparing it from the leaves with forceps, or transferred to X-ray film using sticky transparent tape. The fungal as well as leaf tissue directly below these colonies, except for regions directly exposed to the incubation solution, was homogenized in liquid nitrogen. The radioactivity of plant and fungal material was measured in $3 \mathrm{ml}$ scintillation liquid (Mulsifier-Safe, Canberra Packard, Frankfurt/M., Germany) and calculated on the basis of fresh weight (fw). Additionally, the incubation liquid was measured before and after the 3-day incubation period using a scintillation counter (Packard Tri Carb Liquid Scintillation Spectrometer C2425, Canberra Packard). Quenching was calculated by standards (Control No. 1408, Quenched Carbon-14-Standards Set, Beckmann, München, Germany). The linear regression of the resulting curve was: $y=81605.5 x+$ 130031 with $P<0.1 \%$.

Samples of each gm stage were additionally detached from the leaves with sticky transparent tape. The leaves without mycelia and the tapes bearing mycelium were transferred to an X-ray film (Hyperfilm-MP Amersham, Braunschweig, Germany) and incubated for 21 days at $70^{\circ} \mathrm{C}$.

Histological investigations. For clearing and fixing the leaves, a mixture of 50\% ethanol, $45 \%$ acetic acid (100\%), and 5\% formaldehyde $(37 \%)$ was used for at least $24 \mathrm{~h}$. For the staining of callose, the leaves were transferred to an ice-cold solution as above for $1 \mathrm{~h}$ and stained using $0.5 \%$ resorcin-blue in $\mathrm{K}_{3} \mathrm{PO}_{4}$ buffer $\left(0.1 \mathrm{~mol} \mathrm{l}{ }^{-1}\right.$, $\mathrm{pH} 12.5)$ for $6 \mathrm{~h}(11,12)$. The Coomassiebrilliant blue staining for proteins in the leaves (45) was modified (0.6\% Coomassie-brilliant blue R250 in methanol, $15 \%$ TCA:staining bath, 1:1, $12 \mathrm{~h}$ ) and the staining for pectin (33) was adapted for the use of fixed leaf material by varying the incubation time $(2 \mathrm{~h}$ in hydroxilamine solution $+15 \mathrm{~min}$ after addition of ethanol:hydrochloric acid, 1:2) $+1 \mathrm{~h}$ in ferrite chlorite solution (10 g ferrite-chlorite in $60 \%$ ethanol-hydrochloric acid), followed by a 1-h incubation in hot acid methanol.

The stained material was embedded in gelatin $(12 \%$ for $24 \mathrm{~h}$ and $25 \%$ for $12 \mathrm{~h}$, both at $\left.40^{\circ} \mathrm{C}\right)$, cut $(30 \mu \mathrm{m})$ using a cryomicrotome (Frigomobil Modell 1206, Reichert-Jung, Nußloch, Germany), and transferred to a lactoglycerine solution (lactic acid:glycerine:distilled water, 1:1:1) for further microscopy (Axioskop, Zeiss, Oberkochen, Germany).

\section{RESULTS}

The translocation of stain-solution and ${ }^{14} \mathrm{C}$-sucrose from the host to the different generative stages of the pathogen showed an interesting uniform pattern. For the translocation experiments, sodium fluorescein, which caused a yellow fluorescence of the mycelia (Fig. 2), showed bet- 
ter results than eosin $\mathrm{G}$ or trypan-blue for transport within the leaves, for leaf turgor, and for translocation from the leaf to the mycelium. Application of trypan-blue resulted in increased aging and wilting of the leaves.

Incubation at stage one (gm1) for 3 days allowed nearly unhampered translocation. The stain was equally distributed within the hyphae of the entire colony, although with a slightly higher concentration in the primordia (Fig. 2A). In contrast, the mycelium of stage three (gm3) showed slight fluorescence, the stain being concentrated within the fruit bodies (Fig. 2B) and rarely in directly associated hyphae.

The translocation of ${ }^{14} \mathrm{C}$-sucrose enabled quantification of the translocation process. Compared to the non-infected control leaves $\left(6 \mathrm{~Bq} \mathrm{~g}^{-1} \mathrm{fw}\right)$, the infected leaves (with haustoria) showed a higher incorporation activity (Table 1), which then decreased depending on the cleistothecia development of the pathogen, which was removed just before counting: $399 \mathrm{~Bq} \mathrm{~g}^{-1}$ fw (leaf under gm1) and $197 \mathrm{~Bq} \mathrm{~g}^{-1}$ fw (leaf under gm3).

The concentration of ${ }^{14} \mathrm{C}$ was much higher in all mycelial stages removed from each leaf segment investigated, as compared to the leaf segments underlying powdery mildew colonies (Table 1). Its incorporation was reduced from gm1 to gm3 (Table 1). This was not a result of a reduced transport capacity within the leaves, because the activity difference of the comparable leaf segments was reduced by a factor of two, while that of the mycelium was reduced by a factor of 9 . While gm1 showed a broad distribution of radioactivity throughout the entire mycelium (Fig. 3A), the ${ }^{14} \mathrm{C}$-activity was concentrated within the cleistothecia (Fig. 3B) beginning with the gm2 stage.

The translocation of material (nutrients) from the host to the pathogen was initially high (gm1) and subsequently reduced in the course of cleistothecia development and maturation (gm2; Fig. 3). Histochemical investigations comparing the haustorial complexes of the vegetative mycelium and the generative stages verify that the extrahaustorial matrix enlarges during the development of the fruit bodies. Whereas the haustorial matrix of the vegetative mycelium is nearly indistinguishable from the haustorial wall with light microscopy (Fig. 4A), that of the generative mycelia was readily discernible in the first stage (Fig. 4B). The matrix enlarged during cleistothecial development (Fig. 4C). Given the fact that brownish-colored epidermal cells were observed, this suggests the production of phenolic metabolites by the host cells.

With Coomassie-blue staining, papillae could occasionally be detected around the haustorial neck of vegetative mycelium as well as around those of the first generative stage (gm1; Fig. 4). With the growth and further maturation of the cleistothecia (gm2), the number as well as the thickness of these papillae increased (data not shown). Callose was also deposited outside of the extrahaustorial matrix by the host (Fig. 5), increasing with pronounced cleistothecia development as verified by resorcin-staining. Haustoria of gm3 showed up to $34 \%$ encasement. Pectin was never found by staining methods during these processes.

Detached mycelium, without any contact with the host, of every developmental stage formed a high frequency of dark fruit bodies $(95 \%)$. However, only mycelia of gm2 and $\mathrm{gm} 3$ were able to produce ascospores with a germination rate comparable to that of the field control $(75 \%)$. Mycelia of the first developmental stage never produced ascospores within cleistothecia.

\section{DISCUSSION}

Generative propagation is an important part of the life cycle of many fungi. The switch from vegetative to generative growth is triggered primarily by seasonal changes of climatic conditions or changes in composition of metabolites. The generative mode of reproduction offers genetic advantages $(30,44)$ and allows survival under unsuitable environmental conditions
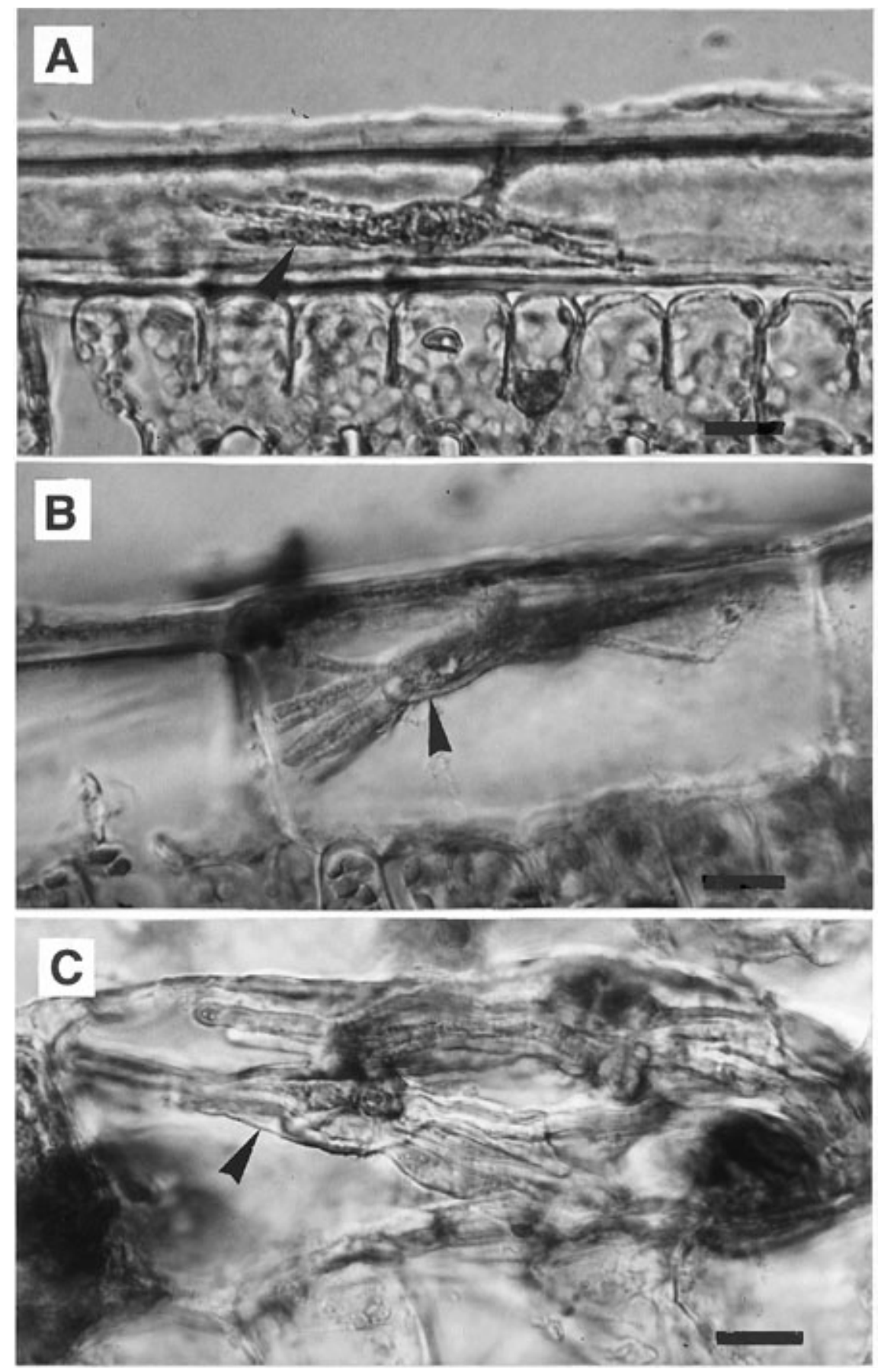

Fig. 4. Haustoria and extrahaustorial matrices (arrow) of Blumeria graminis under (A) vegetative mycelium, (B) generative mycelium ( $\mathrm{gm}$ ) stage 1, and (C) $\mathrm{gm} 3$. Bar $=10 \mu \mathrm{m}$. 
or, in absence of the host, as dormant stages (6). Cleistothecia of $B$. graminis have been discussed in this context $(17,25)$. Ascospores released in autumn infect winter cereals $(4,13)$. During the host's vegetation period, however, this type of sporulation is of minor importance for the spread of the parasite $(14,16,25,29,43)$. There are no data available concerning the nutrition flow from host to parasite and dependency of the fungus on host metabolites during the development of the generative mycelium.

Fruit bodies of gm1 never developed ascospores in vitro when detached from the host. Those of gm2 were able to produce asci as well as ripe ascospores. These data led to the idea that a certain nutrition supply is essential at the early stages of the generative development of mildew fungi, before cleistothecia are macroscopically visible.

The use of labeled metabolites proved that translocation from the host through the haustoria into the vegetative mycelium occurred (2). We applied ${ }^{14} \mathrm{C}$-labeling as well as stains to leaves bearing the generative stages of $B$. graminis f. sp. tritici to calculate the period during which a transport from the host to the parasite takes place in vitro. The fact that gm1 was highly radioactive and that the labeling was distributed equally within the mycelium of a colony demonstrated the high requirement for nutrients of the fungus during this developmental stage. An interruption of the nutrient flow prevented the ripening of ascospores. At the onset of fruit body growth (gm2), the fungus had stored enough metabolites for subsequent ascospore development. As a consequence, the need for nutrients from the host decreased and the fungus was able to complete development of cleistothecia and ascospores independent of the host. The stored metabolites might additionally be transferred from the mycelium to the cleistothecia

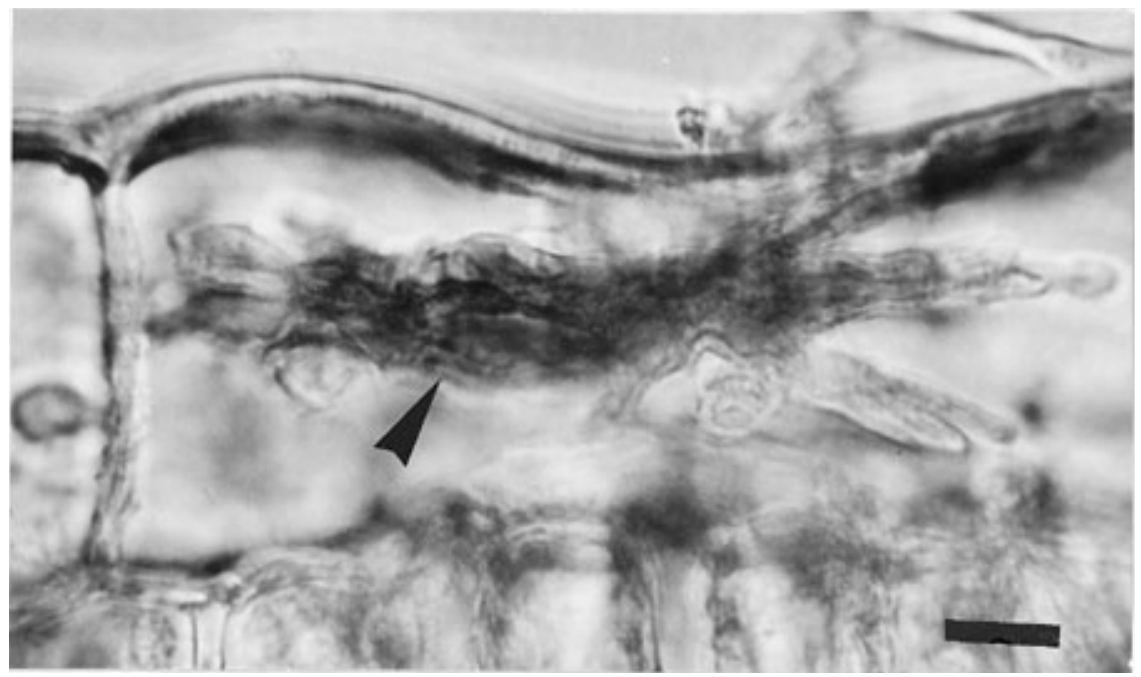

Fig. 5. Callose encasement of Blumeria graminis haustoria at generative mycelium stage 3 (resorcin blue). $\mathrm{Bar}=10 \mu \mathrm{m}$. when the nutrition supply from the host is Metabolite translocation from mycelium to developing fruit bodies has also been shown for Flammulina velutipes (18) and Faveolus arcularius (42). In both cases, proteins were hydrolyzed in the mycelium and transported into the fruit bodies as amino acids.

Colonies bearing microscopically small primordia (gm1) formed, after detachment from the leaf, dark cleistothecia in which no ascospore production took place. This implies that the metabolites stored within stage were not sufficient for a complete generative sporulation. Generative as well as vegetative sporulation have a specific cient translocation of metabolites to cleistothecia has taken place, ascospore differentiation depends strongly on the environment (16). There is no constituent dormancy (9), characterized by a reversible hypometabolism in the case of cleistothecia (41), but an exogenous dormancy, in which unsuitable environmental but not physiological or biochemical conditions are determinative (10).

As shown by the morphological investigations, the extrahaustorial matrix increased in size with pronounced development of the generative mycelium. The distance for nutrients to pass by diffusion was greater. The translocation of nutrients was additionally reduced by increased callose encasement of the haustoria, and to a lesser degree of the haustorial fingers, because this macromolecule is not permeable for smaller molecules $(3,19)$.

In addition, callose encasement $(3,36$, $37,40)$ and papillae formation are discussed as plant defense reactions $(1,8,46)$, as both develop in an analogous way (38). This correlates well with the interpretation of encasement as a normal defense reaction in incompatible host-pathogen-interactions at naturally or experimentally interrupted. the mycelium up to that developmental nutrient requirement. As soon as a suffi- early developmental stages $(3,7,21)$, or in incompatible interactions induced by fungicides $(22,27,39)$.

Damaged haustoria are encased by their hosts $(20,23,30)$. This led to the assumption that the haustoria of generative mildew mycelium show reduced functional activity, due to the lower nutrition requirement with the onset of gm2, a stage that allows further fruit body development, including ripe ascospores, without contact to the host. The lower efflux from the leaf into the haustoria could be a result of lower haustorium activity or reduction in defense suppression in combination with the high metabolic activity of the associated leaf tissue (15), allowing an increase in defense reactions of even the senescent host leaf in this compatible interaction.

\section{ACKNOWLEGMENTS}

We thank H. Boyle and S. Wagner for critical comments during the work, for discussion, and for advice on English syntax.

\section{LITERATURE CITED}

1. Aist, J. R., Kunoh, H., and Israel, H.W. 1979. Challenge appressoria of Erysiphe graminis fail to breach preformed papillae of compatible barley cultivar. Phytopathology 69:12451250.

2. Aked, J., and Hall, J. L. 1993. The uptake of glucose, fructose and sucrose into pea powdery mildew (Erysiphe pisi DC.) from the apoplast of pea leaves. New Phytol. 123:277282.

3. Allen, F. H. E., and Friend, J. 1983. Resistance of potato tubers to infection by Phytophthora infestans: a structural study of haustorial encasement. Physiol. Plant Pathol. 22:285-292.

4. Aust, H.-J. 1981. Über den Verlauf von Mehltauepidemien innerhalb des Agrar-Ökosystems Gerstenfeld. Acta Phytomedica 7 Verlag Paul Parey, Berlin und Hamburg.

5. Bhandari, N. N, and Mukerji, K. G. 1993. The fungal haustorium. Pages 163-289 in: The Haustorium. N. N. Bhandari and K. G. Mukerji, eds. Research Studies Press Ltd., John Wiley and Sons Inc., New York.

6. Bonner, J. T. 1958. The relation of spore formation and recombination. Am. Nat. 92:193-200.

7. Bracker, C. E., and Littlefield, L. J. 1973. Structural concepts of host-pathogen interfaces. Pages 159-318 in: Fungal Pathogenicity and the Plant's Response. R. J. W. Byrde and C. V. Cutting, eds. Academic Press, London.

8. Bushnell, W. R., and Berquist, S. E. 1975. Aggregation of host cytoplasm and the formation of papillae and haustoria in powdery mildew of barley. Phytopathology 65:310318.

9. Cherewick, W. J. 1944. Studies on the biology of Erysiphe graminis DC.. Can. J. Res. Sect. C Bot. Sci. 22:52-86.

10. Dahlberg, K. R., and van Etten, J. L. 1982. Physiology and biochemistry of fungal sporulation. Annu. Rev. Phytopathol. 20:281301.

11. Eschrich, W. 1961. Untersuchungen über den Ab- und Aufbau der Callose. Z. Bot. 49:153218.

12. Eschrich, W., and Currier, H. B. 1964. Identification of callose by its diachrome and fluorochrome reactions. Stain Technol. 39:303-307.

13. Frauenstein, K., Frohns, M., and Haase, E. 1980. Untersuchungen zur Reifezeit der Kleistothezien von Erysiphe graminis DC. f. 
sp. tritici Marchal. Arch. Phytopathol. Pflanzenschutz 16:89-93.

14. Gorlenko, M. 1950. Biologische Besonderheiten des Echten Mehltaus (Erysiphe graminis DC. f. sp. tritici Marchal) in der UDSSR. Bolez. rast. i vneshniaja s eda 27:81108.

15. Götz, M. 1996: Zur vegetativen und generativen Entwicklung der obligat biotrophen Parasiten in den Pathosystemen Triticum aestivum/Blumeria graminis und Phaseolus vulgaris/Uromyces appendiculatus. Dissertation Technische Universität Braunschweig.

16. Götz, M., Friedrich, S., and Boyle, C. 1996. Cleistothecia as a source of infection of wheat during summer. Z. Pflanzenkr. Pflanzenschutz 103 (2) 134-141

17. Graf-Marin, A. 1934. Studies on powdery mildews of cereals. Mem. Cornell Univ. Agric. Exp. Sta 157:1-48.

18. Gruen, H. E., and Wong, W. M. 1982. Distribution of cellular amino acids, protein, and total organic nitrogen during fruit body development in Flammulina velutipes. II. Growth in potato-glucose solution. Can. J. Bot. 60:1342-1351

19. Hancock, J. G., and Huisman, O. C. 1981. Nutrient movement in host-pathogen systems. Annu. Rev. Phytopathol. 19:309-331.

20. Heath, M. C. 1988. Effect of fungal death or inhibition induced by oxycarboxin or polyoxin $\mathrm{D}$ on the interaction between resistant or susceptible bean cultivars and the bean rust fungus. Phytopathology 78:1454-1462.

21. Heath, M. C., and Heath, J. B. 1971. Ultrastructure of an immune and a susceptible reaction of cowpea leaves to rust infection. Physiol. Plant Pathol. 1:277-287.

22. Heller, A., Grossmann, F., Frenzel, B., and Hippe, S. 1990. A cytological study of the development of Erysiphe graminis in its host barley as influenced by the two fungicides ethirimol and propiconazole. Can. J. Bot. 68:2618-2628.

23. Hirata, K. 1971. Calcium in relation to the susceptibility of primary barley leaves to powdery mildew. Pages 207-228 in: Morphological and Biochemical Events in PlantParasite Interaction. S. Akai and S. Ouchi, eds. Phytopathol. Soc. Jpn., Tokyo.
24. Jenkyn, J. F., and Bainbridge, A. 1978. Biology and pathology of cereal powdery mildews. Pages 284-317 in: The Powdery Mildews. D. M. Spencer, ed. Academic Press, London.

25. Koltin, Y., and Kenneth, R. 1970. The role of sexual stage in the over-summering of Erysiphe graminis DC. f. sp. hordei Marchal under semi-arid conditions. Ann. Appl. Biol. 65:263-268.

26. Mackie, A. J., Roberts, A. M., Callow, J. A, and Green, J. R. 1991. Molecular differentiation in pea powdery-mildew haustoria. Planta 183:399-408

27. Maffi, D., Cozzi, F., Violini, G., Bassi, M., and Conti, G.G. 1995. Ultrastructural studies of the effects of tetraconazole on the barleypowdery mildew host pathogen complex. Mycol. Res. 99 (7):799-805.

28. Manners, J. M. 1989. The host-haustorium interface in powdery mildew. Aust. J. Plant Physiol. 16:45-52.

29. Mosemann, J. G., and Powers, H. R. 1957. Function and longevity of cleistothecia of Erysiphe graminis f. sp. hordei. Phytopathology 47:53-56.

30. Muenchow, G. 1978. A note of the timing of sex in asexual/sexual organisms. Am. Nat. 112:774-779.

31. Rabbinge, R., Jorritsma, I. T. M., and Schans, J. 1985. Damage components of powdery mildew in winter wheat. Neth. J. Plant Pathol. 91:235-247.

32. Rees, T. A. P. 1984. Sucrose metabolism. Pages 53-73 in: Storage Carbohydrates in Vascular Plants. D. H. Lewis, ed. Cambridge University Press, Cambridge.

33. Reeve, R. M. 1959. A specific hydroxylamine-ferric chloride reaction for histochemical localization of pectin. Stain Technol. 34:209-211.

34. Richter, G. 1988. Stoffwechselphysiologie der Pflanzen, 5. Auflage. Georg Thieme Verlag, Stuttgart.

35. Royse, D. J., Gregory, L. V., Ayres, J. E., and Cole, H. 1980. Powdery mildew of wheat: relation of yield components to disease severity. Can. J. Plant Pathol. 2:131-136.

36. Skou, J. P. 1982. Callose formation responsible for the powdery mildew resistance in bar- ley with genes in the ml-o locus. Phytopathol. Z. 104:90-95.

37. Skou, J. P., Jørgensen, J. H., and Lilholt, U. 1984. Comparative studies of callose formation in powdery mildew compatible and incompatible barley. Phytopathol. Z. 109:147168.

38. Smolka, S. 1985. Cytologische Untersuchungen zur Wirkung systemischer Fungizide auf den Wirt-Parasit-Komplex Gerste-Echter Mehltau (Erysiphe graminis f. sp. hordei Marchal). Dissertation, Georg-August-Universität Göttingen.

39. Smolka, S., Ebrahim-Nespat, F., and Wolf, G 1988. Elektronenmikroskopische Untersuchungen zur Beeinflussung der Wirt-Parasit-Beziehung Gerste-Mehltau durch Triadimenol (baytan). Z. Pflanzenkr Pflanzenschutz 95:270-284.

40. Stark-Urnau, M., and Mendgen, K. 1995 Sequential deposition of plant glycoproteins and polysaccharides at the host-parasite interface of Uromyces vignae and Vigna sinensis. Evidence for endocytosis and exocytosis. Protoplasma 186:1-11

41. Sussmann, A. S., and Douthit, H. A. 1973. Dormancy in microbial spores. Annu. Rev. Plant Physiol. 24:311-352.

42. Terashita, T., Kitamoto, Y., Matsumoto, T. Hosoi, N., Kono, M., and Ichikawa, Y. 1984 Nitrogen metabolism in Favolus arcularius changes in composition of free- and proteinamino acids during development of the mycelium and fruiting bodies. Trans. Mycol. Soc. Jpn. 25:175-181

43. Turner, D. M. 1956. Studies on cereal mildew in Britain. Trans. Brit. Mycol. Soc. 39:459506.

44. Warner, R. 1978. Sexual-asexual evolutionary equilibrium? Am. Nat. 112:960-962.

45. Wolf, G., and Fric, F. 1981. A rapid staining method for Erysiphe graminis f. sp. hordei in and on whole barley leaves with a proteinspecific dye. Phytopathology 71:596-598.

46. Zeyen, R. J., and Bushnell, W. R. 1979. Papilla response of barley epidermal cells caused by Erysiphe graminis: rate and method of deposition determined by microcinematography and transmission electron microscopy. Can. J. Bot. 57:898-913. 